DEMOGRAPHIC RESEARCH

VOLUME 35, ARTICLE 32, PAGES 961-990

PUBLISHED 29 SEPTEMBER 2016

http://www.demographic-research.org/Volumes/Vol35/32/

DOI: 10.4054/DemRes.2016.35.32

Research Article

Cohabitation among secular Jews in Israel: How ethnicity, education, and employment characteristics are related to young adults' living arrangements

\title{
Avital Manor
}

\section{Barbara S. Okun}

(C)2016 Avital Manor \& Barbara S. Okun.

This open-access work is published under the terms of the Creative Commons Attribution NonCommercial License 2.0 Germany, which permits use, reproduction \& distribution in any medium for non-commercial purposes, provided the original author(s) and source are given credit.

See http:// creativecommons.org/licenses/by-nc/2.0/de/ 


\section{Contents}

1 Introduction 962

$2 \quad$ Theoretical background 963

2.1 Cohabitation 963

2.2 Economic theory of comparative advantage 964

2.3 The career uncertainty hypothesis 964

2.4 Ideational theories 966

$3 \quad$ The Israeli setting 967

3.1 Economic theory of comparative advantage 969

3.2 Young adults' career uncertainty and economic position 970

$\begin{array}{ll}3.3 & \text { Ideational theories }\end{array}$

$4 \quad$ Current research $\quad 971$

4.1 Research hypotheses 971

4.2 Data 973

$\begin{array}{lll}4.3 & \text { Sample } & 973\end{array}$

$\begin{array}{lll}4.4 & \text { Methods } & 974\end{array}$

4.5 Measurements $\quad 975$

$\begin{array}{lll}4.6 & \text { Results } & 976\end{array}$

$5 \quad$ Discussion and conclusions 981

5.1 Economic theory of comparative advantage 981

5.2 Career uncertainty 982

$\begin{array}{lll}5.3 & 982\end{array}$

6 Acknowledgments 983

$\begin{array}{ll}\text { References } & 985\end{array}$

$\begin{array}{ll}\text { Appendix } & 990\end{array}$ 


\title{
Cohabitation among secular Jews in Israel: How ethnicity, education, and employment characteristics are related to young adults' living arrangements
}

\author{
Avital Manor ${ }^{1}$ \\ Barbara S. Okun ${ }^{2}$
}

\begin{abstract}
BACKGROUND

Economic and ideational theories offer various explanations for the roles of ethnicity, education, and employment characteristics in determining cohabitation behavior in various contexts.
\end{abstract}

\section{OBJECTIVE}

We focus on young, native-born secular Jewish adults in Israel, a subpopulation that has been shown to display Second Demographic Transition behaviors. Within this group we investigate whether a person's ethnicity, education, and employment characteristics are associated with their current living arrangements.

\section{METHODS}

We employ multinomial logit regression on a series of five annual data files from the Israeli Social Survey (ISS), 2005-2009. We consider the association between various explanatory variables and the odds of cohabitation vs. being married as well as the odds of cohabitation vs. being unpartnered.

\section{RESULTS}

Higher odds of cohabiting vs. being married are significantly associated with (1) tertiary education and student status, among men and women; (2) having accumulated fewer than five years of work experience, among men; (3) working full-time, among women; and (4) European-American ethnicity and being third-generation Israeli, among women. Higher odds of cohabiting vs. being unpartnered are significantly associated with (1) tertiary education and student status, among men; and (2) working full-time, among men.

\footnotetext{
1 Formerly of the Hebrew University of Jerusalem, Department of Sociology and Anthropology, Demographic Studies and Myers-JDC-Brookdale Institute, Israel. E-Mail: manor124@gmail.com.

${ }^{2}$ The Hebrew University of Jerusalem, Department of Sociology and Anthropology, Demographic Studies, Israel. E-Mail: barbara.okun@mail.huji.ac.il.
} 


\section{CONCLUSIONS}

We suggest that in Israel a multicausal model that accounts for both economic and ideational factors is appropriate. While limited work experience among men encourages cohabitation as an alternative to marriage, as suggested by some economic theories, associations between cohabitation and educational characteristics (among men and women) as well as ethnicity (among women) are more consistent with ideational theories.

\section{Introduction}

In the last four decades family-related behavior and attitudes have undergone major shifts in Western societies. This set of changes is often referred to in the literature as the Second Demographic Transition (SDT). One of the characteristics of this transition has been the rise of nontraditional living arrangements, among them unmarried cohabitation (Sobotka 2008; Lesthaeghe 2010). Two economic theories and one ideational theory offer an explanation for the spread of cohabitation.

According to the economic theory of comparative advantage, the rise of cohabitation is the result of an increase in women's education and labor force participation, which have reduced the gains from marriage (Becker 1991; Blossfeld 1995). An alternative economic explanation focuses on the rise of young adults' career uncertainty, particularly among less educated young men, and the resulting decline in marriage and increase in cohabitation (Oppenheimer 1988; Oppenheimer 2003). Ideational theories stress the role of secular individualistic attitudes (associated with higher education) in the recent spread of cohabitation (Lesthaeghe and Surkyn 1988; Lesthaeghe 2010).

Cohabitation in Israel has been increasing in the last decade, especially among the secular and less religious populations (Bystrov 2012; Manor 2013; Okun 2016). This study analyzes a series of five annual data files from the Israeli Social Survey (ISS), 2005-2009. A multinomial logit regression method is employed to examine how ethnicity, education, and employment characteristics are related to living arrangements among secular Jews in Israel. 


\section{Theoretical background}

\subsection{Cohabitation}

Historically, cohabitation has been practiced mainly by the poor, who could not afford to marry, or by couples who could not legally be married (e.g., separated individuals who were not able to divorce) (Kiernan 2004; Sobotka and Toulemon 2008). However, the new form of cohabitation that came to the fore in Sweden and Denmark during the 1960s and in northern and western European countries, North America, and Australia and New Zealand in the 1970s could be termed 'nubile cohabitation.' In this type of cohabitation young people in their twenties or early thirties live together as a prelude to marriage or as an alternative to it. ${ }^{3}$ Much of the decline in marriage that has occurred in many European countries in recent decades is related to the rise in this type of cohabitation (Kiernan 2000) and this is also true for the Unites States (Bumpass and Lu 2000; Raley 2000).

Today the phenomenon of unmarried couples living together has become widely accepted across Europe. In many countries premarital cohabitation has become the norm and direct marriage is practiced mainly by religious and ethnic minorities (Sobotka 2008). In France the proportion of couples beginning their union with unmarried cohabitation increased from $10 \%$ to $90 \%$ during the period $1965-1995$ (Sobotka and Toulemon 2008). Cohabitation has also become strikingly common in the Nordic countries of Denmark, Sweden, and Finland. Southern European countries, on the other hand, still exhibit relatively low levels of cohabitation (Kiernan 2004).

There is a debate in the literature (Heuveline and Timberlake 2004; Perelli-Harris 2014) regarding whether, in certain contexts, cohabitation may be seen as "indistinguishable" from marriage (Kiernan 2001: 3). One important dimension associated with the extent to which cohabitation is 'marriage-like' relates to childbearing patterns within cohabiting unions. While childbearing within cohabitation has become increasingly common in recent decades in many parts of Europe and the United States, and accounts for a growing proportion of nonmarital childbearing, patterns of childbearing differ between cohabiting and married couples: for example, the educational gradient of childbearing among cohabiting couples (as well as among unpartnered women) is more negative than among married couples. Differences in childbearing patterns between married and cohabiting couples have led some scholars to conclude that even in countries where cohabitation is very widespread it still differs from marriage in terms of its social consequences for children and families (Bumpass

\footnotetext{
${ }^{3}$ In addition to nubile cohabitation, divorce and widowhood were less frequently followed by remarriage and often followed by postmarital cohabitation (Lesthaeghe 2010).
} 
and Lu 2000; Perelli-Harris et al. 2010). The following sections will discuss theoretical and empirical research concerning the correlates of nontraditional living arrangements.

\subsection{Economic theory of comparative advantage}

Becker (1991) views marriage as an economic contract allowing each partner to further specialize in the field where $\mathrm{s}$ /he has a comparative advantage: that is, the man specializes in labor market activities and the woman specializes in household activities. According to this view, the growing economic independence of women has reduced the gains from marriage, thereby leading to the spread of other living arrangements, among them consensual unions (unmarried cohabitation).

Men with high earning potential gain more from marriage than other men because they can attract women with high nonmarket productivity and because their opportunity costs of being unmarried and of having no wife to take on household responsibilities are especially high (Becker 1991). Accordingly, we can expect higher educational attainment among men to be associated with higher odds of marriage vs. cohabitation. By contrast, women with high earning power are more likely than other women to choose alternatives to marriage because the opportunity costs of marrying and spending more time on housework are particularly high for them. This factor is important in making the comparison between marriage and cohabitation because we can expect cohabitation to be associated with less gender inequality in the division of household labor than marriage (Batalova and Cohen 2002; Baxter 2005; Dominguez Folgueras 2013). Since the increasing educational attainment of women and their resulting improved career opportunities are considered the main factors in women's growing economic independence, it is generally to be expected, if the theory of comparative advantage is valid, that empirical evidence will show that more educated women are more likely to enter cohabitation or to remain unpartnered (as opposed to entering marriage) than less educated women (Blossfeld 1995; Lesthaeghe 1998: 10). The theory does not suggest how education or labor market activity might be associated with the odds of cohabitation vs. being unpartnered. The social and economic significance of cohabitation in terms of comparative advantage to women and men in the Israeli context will be discussed further below.

\subsection{The career uncertainty hypothesis}

Oppenheimer's theory of marriage and cohabitation, as elaborated in Kalmijn (2011), discusses effects of men's education and labor market activity on union formation. 
Because men's income and earning ability are critical for the formation of an independent household, men's higher income will allow them to marry; if they cannot afford to do so, or if there is too much uncertainty about their future economic prospects and lifestyles (e.g., they are still students, or hold 'stopgap' jobs), they may have to cohabit. Cohabitation is seen as a cheaper, temporary form of union: a union that is easier to dissolve than marriage and one in which uncertainty in terms of lifestyle and economic prospects is more tolerable. Thus Oppenheimer's theory suggests that men's higher education (an indication of long-term economic prospects) and work stability will be associated with reduced odds of cohabitation vs. marriage; men's school enrollment and limited work experience will be associated with increased odds of cohabitation vs. marriage.

Oppenheimer's research focuses mostly on men, because men are seen as the main breadwinners; however, her theory can be extended to women. The theory's implications for women may be particularly relevant in contexts where gender wage gaps are small among young adults and where women do contribute substantially to household income and are expected to participate in the labor market with few work interruptions. In these contexts we would expect to see the same types of relationships between education, labor market activity, and the odds of cohabitation vs. marriage as described above for men. However, we might expect that the magnitude of these effects would be smaller than among men, for two reasons. First, even working women do not usually provide the bulk of household income for couples; therefore low earnings and high uncertainty about women's earnings may be more tolerable and thus less critical to the marriage vs. cohabitation decision than they are among men. Second, more educated women and those with higher earnings may be able to afford longer search periods for potential mates, thus increasing their odds of cohabitation vs. marriage relative to their less educated counterparts.

If we consider Oppenheimer's theory in terms of cohabitation vs. being unpartnered we would expect men's education and labor market stability to be associated with increased odds of cohabitation; school enrollment and limited work experience would reduce the odds of cohabitation. This follows because, although a 'cheaper' form of union than marriage and one that is easier to dissolve, cohabitation still requires an economic basis and involves a greater level of lifestyle commitment to a partner than being single does. For the reasons discussed above, we might expect to see similar types of associations among women, but perhaps weaker in magnitude than those found among men.

A range of research from the United States, Europe, and Australia is generally supportive of this theoretical framework (Hoem 1986; Carmichael 1995; Kalmijn 2011; Oppenheimer 2003). For example, Oppenheimer (2003) finds that greater work stability decreases the odds of entering cohabitation rather than entering marriage among single 
non-cohabiting men in the United States. In terms of educational attainment among men, Oppenheimer (2003) finds that college education, in comparison to a high school diploma, reduces the odds of entering cohabitation rather than entering marriage. Moreover, a range of evidence based on women and men in the United States, Europe, and Australia indicates that school enrollment was found to have either a positive effect or no effect on entering cohabitation rather than marriage (Hoem 1986; Carmichael 1995; Kalmijn 2011; Oppenheimer 2003).

\subsection{Ideational theories}

Lesthaeghe and Surkyn (1988) argue that in recent decades Western societies have undergone a major shift in values, moving toward secularism, individualism, and postmaterialism. This ideational shift has been shown to progress across cohorts and to be more common among more educated individuals. Lesthaeghe (2010) attributes the rise in nontraditional living arrangements to this cultural change. For example, cohabitation has spread first in more secularized areas, where it has received growing moral acceptability. Cohabitation has also been shown to be linked on the individual level to more liberal attitudes (Lesthaeghe 2010). More liberal attitudes may, in turn, be associated with higher education and with ethnic background, to the extent that ethnic groups differ in their value orientations.

Ideational theories highlight the importance of values and attitudes and place less emphasis on educational attainment per se in the explanation of STD behavior. Nevertheless, these theories do imply that more educated individuals, as well as students who are on their way to becoming more educated, will be the first to adopt nontraditional living arrangement due to the more liberal attitudes they tend to hold. In other words value orientation is expected to mediate the relationships between, on the one hand, educational attainment and student status and, on the other, cohabitation. ${ }^{4}$

Ní Bhrolcháin and Beaujouan (2013) argue that the appearance of educational differentials in current cohabitation or lifetime incidence of cohabitation in a crosssection may depend on the stage of the process of diffusion of this social change. Specifically, in the early stages of the diffusion of cohabitation in Britain, cohabitation was more prevalent among the more highly educated, as they were the forerunners of the process, in accordance with ideational theories. Later, as cohabitation became a more widespread social phenomenon, less educated women closed the gap and even began cohabiting at earlier ages than their more educated counterparts, as they begin all processes of family formation younger (after early completion of education). Empirical

\footnotetext{
${ }^{4}$ Lesthaeghe (1998: 10) argues that, when elaborated on, ideational theories connect expressive individualism to higher education and predict that cohabitation will increase first among the better educated.
} 
findings consistent with this argument are also reported by Rosina and Fraboni (2004), who discovered that cohabitation is more common among more educated young women in Italy, a country still in the relatively early stages of diffusion of cohabitation.

In summary, ideational theories suggest that markers of higher education (educational attainment and status as a student in higher education) are associated with more liberal attitudes toward nontraditional family forms such as cohabitation, among women as well as men. In addition, to the extent that attitudes and values differ across ethnic groups, these theories would predict higher odds of cohabitation as opposed to marriage among women and men from ethnic groups with more liberal attitudes. As single living is also a nontraditional family behavior associated with SDT (Lesthaeghe 2010), it is unclear what the prediction of ideational theories is for the odds of cohabitation vs. single living among more educated individuals, students, or those from ethnic groups with more liberal attitudes. Also, ideational theories do not predict specific associations between work-related variables and living arrangements at the micro-level.

\section{The Israeli setting}

The United Nations Human Development Index ranks Israel as among the "very high human development countries" in education, income, and health (United Nations 2011). In particular, Jewish women in Israel are highly educated and have high labor force participation. Over the years the proportion of women among the highly educated in Israel has increased to the point where they are now overrepresented. In 2009 women comprised $56.5 \%$ of students who received a BA degree from a university, $55.7 \%$ of students who received an MA degree and $49.2 \%$ of students who received a $\mathrm{PhD}$. This is an increase from $39.7 \%, 24.8 \%$, and $15.5 \%$ respectively in 1970 . However, women are still underrepresented in some prestigious areas of study. For example, in 2009 only $34.6 \%$ of students who received a BA degree in mathematics, statistics, and computer sciences were women (ICBS 2012).

The rise in women's education has been accompanied by a rise in women's labor force participation. Women comprised less than a third of the labor force in 1970 (Fogiel-Bijaoui 1999) but this proportion increased to 47\% in 2011 (ICBS 2013). However, despite the high labor force participation of women, they are still considered secondary breadwinners and are expected to combine work and family life (Kraus 2002; Raz-Yurovich 2010).

Israel has often been discussed as a traditional, family-oriented society, even as it is considered a politically and economically modern one (e.g., Lavee and Katz 2003; Peres and Katz 1980). Some have suggested that familism, which is institutionalized in 
Israel through religious family law, serves as a cultural code for dictating the proper life for women and men, emphasizing high fertility, marriage, marital stability, and fertility within marriage (Toren 2003). In the current research context this point is worth emphasizing because, in the absence of civil marriage in Israel, cohabitation is one of the few options for couples who oppose religious marriage.

Among Jews in Israel fertility is very high (TFR of 3.0 in recent years) and nonmarital fertility remains rare ( $4 \%$ of all births to Jewish women in recent years): see ICBS 2014. While it has been suggested that religious traditionalism is weakest among the most educated and secular groups (Fogiel-Bijaoui 2002) and that secular Jews are the forerunners of SDT behaviors, the family remains a strong and central institution even among secular Jews in Israel. For example, instances of being unmarried by age 40 and being childless are on the rise but are still relatively rare, even among secular Jews, and three children is the modal completed family size for (native-born) secular women (Okun 2013). Although marriage among secular Jews is still widespread, age at marriage is not particularly low by developed country standards, perhaps due in part to the mandatory military service of two to three years beginning at age 18 for most women and men. As a result of military service, tertiary-level education is usually postponed to later ages, and completion of degree and family formation often do not occur at very young ages (Okun 2013).

While there have been few studies on cohabitation in Israel (see Katz 2001; Baloush-Kleinman and Sharlin 2004; and Fogel 2005), research does suggest that cohabitation has been spreading among some population groups. For example, while it is nearly absent among Arab and religious Jewish populations in Israel, it is becoming an increasingly common experience among secular Jews. The proportion cohabiting among native-born secular women and men aged 20-34 increased significantly from $6 \%$ in 2002-2005 to 9\% in 2006-2009 (Manor 2013; Okun 2016), although it remains below the OECD-25 average of 12\% in recent years (OECD 2010).

The upward trend in cohabitation among native-born secular Jews is consistent with SDT, and the overall levels of cohabitation are not very low relative to European standards, although most northern and western European countries have much higher levels. Current levels of cohabitation among native-born secular Jews in Israel are close to those in some southern and eastern European populations, which have had slower transitions to cohabitation (Lesthaeghe 2010). Low proportions currently cohabiting are consistent with relatively high proportions ever having cohabited, albeit for short durations (see Bystrov 2012). Moreover, increases in cohabitation among secular Jews are consistent with attitudinal data based on the International Social Survey Programme (ISSP) surveys, which show increases between 1994 and 2003 in approval of nonmarital cohabitation among secular Jews in Israel (Glickman, Oren, and LewinEpstein 2003; Bystrov 2012). 
However, it is important to note that although cohabitation is an increasingly common form of behavior and one that is becoming more socially acceptable among secular Jews, it remains in the form of a 'trial marriage' rather than as a long-term alternative to marriage. In particular, cohabitation in Israel is associated with the absence of children, as well as with low levels of home ownership, relative to married couples (Fogel 2005; Baloush-Kleinman and Sharlin 2004). In this sense cohabitation in the Israeli context may be seen as a relationship form which is not marriage-like; the near absence of childbearing among cohabiters is notable and suggests that the decision to marry is closely tied with subsequent childbearing. That is, the marriage decision can be seen as a 'package' involving not only formalized spousal relations but also a potentially more complex commitment involving children and joint home ownership. Thus cohabitation among secular Jews in Israel may be better understood as a stage before marriage and a form of partnership that requires less investment and less longterm commitment. With these points in mind, we consider the relevance of various theories discussed above in the current context.

\subsection{Economic theory of comparative advantage}

The increasing economic role of Israeli women in the family leaves room to test the theory of comparative advantage, which would suggest that more educated women and those with greater investments in human capital have higher odds of cohabitation vs. marriage than other women. This follows because we expect cohabitation to be associated with less gender inequality in the division of household labor than marriage (Batalova and Cohen 2002; Baxter 2005; Dominguez Folgueras 2013). Moreover, as cohabitation in Israel is not generally associated with childbearing (Fogel 2005) and the vast majority of childbearing occurs within marriage (Okun 2013; 2016), total time spent on household labor (housework and childcare) is expected to be lower among cohabiting as opposed to married couples. Thus we can expect women in cohabiting relationships to face fewer dilemmas stemming from work-family balance, which might be particularly attractive for women who have invested and are continuing to invest in the labor market and who are not yet interested in having children. To the extent that, for men, marriage more than cohabitation is associated with greater specialization in the labor market, it should be more attractive for those who have invested and continue to invest more heavily in human capital. 


\subsection{Young adults' career uncertainty and economic position}

Bar-Haim, Blank, and Shavit (2013) find that the distribution of occupations in the Israeli labor market has changed little during the period of major educational expansion in the 1990s and 2000s. Consequently, in 2008 the more educated (native-born Jewish and Arab young adults aged 28-34) had to settle for less prestigious jobs than their counterparts in earlier periods. In addition, the bargaining position of the less educated in the labor market has weakened, leading to a decline in their average income.

Thus it would seem that Oppenheimer's theory could be relevant, in that less economically stable young people would be more likely to enter into and remain in a cohabiting rather than a marital union, especially because in the Israeli context cohabitation is seen as a more temporary form of union and one which usually does not involve childbearing or home ownership. Therefore greater levels of economic and lifestyle uncertainty may be more tolerable for couples considering cohabitation as opposed to marriage. This line of reasoning is supported by Raz-Yurovich (2010), who finds that, among Jewish men and women in Israel, economic instability reduces the odds of first marriage, while higher earnings and greater accumulated years of education increase the odds of first marriage; however, her research did not consider specifically the odds of cohabitation vs. marriage.

Moreover, economic and lifestyle uncertainty may reduce the odds of cohabitation vs. being unpartnered, because cohabitation does require some basis of economic stability, even if less than for marriage. In the Israeli context we might expect these effects to be stronger for men than for women.

\subsection{Ideational theories}

Research indicates that recent birth cohorts in Israel, as compared to their counterparts born in earlier periods, are more positively oriented toward tolerance for diversity in lifestyle and hold more positive attitudes toward personal autonomy, freedom of expression, and gender equality (Bystrov 2012); these value changes were identified among secular Jews in particular (Glickman, Oren, and Lewin-Epstein 2003). Recent research also suggests that ideational change may have played an important role in declining marriage rates among the Jewish population of Israel in recent decades; Schellekens and Gliksberg (2013) find that marriage decline can be understood in terms of attitudinal change brought about by the demographic dynamic of cohort succession. Moreover, marriage rates first started to decline among the cohort of women born in 1965-69 and the cohort of men born in 1960-64 (Schellekens and Gliksberg 2013). These changes in marriage rates coincide with a steep rise in the proportion of those 
who have ever cohabitated observed among people born in the mid-1960s (Bystrov 2012).

Within the secular Jewish population, it may be that educational and ethnic differences in values and attitudes are important. The secular Jewish population is a particularly well-educated group within Israel (Okun 2016); this fact, together with the overall increases in educational levels across cohorts, leaves room to test whether more educated women and men, as well as those who, as students, are on their way to attaining higher degrees, are more likely to participate in cohabiting unions. In terms of ethnicity, the Jewish population is divided into two main ethnic groups: Jews of Asian or North African origin (Sephardim) and Jews of European or American origin (Ashkenazim). The African-Asian population maintains more traditional family behavior and attitudes (Friedlander and Goldscheider 1978; Okun and Khait-Marelly 2008) and has a family-oriented culture, where traditional gender roles and strong ties with relatives are more common, whereas the European-American culture is more often individual-oriented (Katz 2001). Therefore we may find ethnic differences in the odds of participating in cohabiting unions.

\section{Current research}

The focus of this research is on young adults who never married or who are in their first marriage. A multinomial regression model is employed to examine how ethnicity, school enrollment status, educational attainments, and employment characteristics are related to their living arrangements.

\subsection{Research hypotheses}

In light of the various theories discussed above in the context of the secular Jewish population of Israel, we put forward several complementary and competing hypotheses, as follows. 


\subsubsection{Educational characteristics and labor market activity and experience: Cohabitation vs. marriage}

\section{Among men}

Both the theory of comparative advantage and the theory of career uncertainty predict that more educated men and those who work full-time and who have accumulated more years of work experience will have lower odds of cohabitation vs. marriage. By contrast, ideational theories predict that more educated men will have higher odds of cohabitation vs. marriage. In terms of student status, the career uncertainty theory as well as the ideational theories predict a positive association between being a student and the odds of cohabitation vs. being married.

\section{Among women}

The theory of comparative advantage predicts that, unlike their male counterparts, more educated women and those who work full-time and who have accumulated more years of work experience will have higher odds of cohabitation vs. marriage. Ideational theories also predict that more educated women will have higher odds of cohabitation vs. marriage. By contrast, the career uncertainty hypothesis has predictions for women that are opposite to those of the theory of comparative advantage and ideational theories, albeit effects for women are hypothesized to be weaker than for men. In terms of student status, the theory of career uncertainty and the ideational theories predict that student status will be associated with higher odds of cohabitation vs. being married.

\subsubsection{Educational characteristics and labor market activity and experience: cohabitation vs. being unpartnered}

The career uncertainty hypothesis predicts that for both men and women higher levels of education, greater work experience, and full-time employment will be associated with higher odds of cohabitation vs. being unpartnered, while student status will be associated with lower odds of cohabitation vs. being unpartnered. The other theories do not have unambiguous predictions regarding comparisons between cohabitation and being unpartnered. 


\subsubsection{Ethnic differences: cohabitation vs. marriage}

According to ideational theories, women and men of African-Asian ethnicity, as compared to those of European-American ethnicity or third-generation Israelis, would have lower odds of cohabitation vs. marriage.

\subsection{Data}

We analyze a series of five annual data files from the ISS, 2005-2009. Every year a sample of about 7,500 individuals is drawn by the Israel Central Bureau of Statistics (ICBS), representing the adult (20 and over) population of Israel. Questionnaires are administered in face-to-face interviews, resulting in survey response rates of over $80 \%$. Survey weights are computed for the purpose of correcting for selective nonresponse in order to ensure that the sample is representative of the adult population of Israel. Statistical estimates presented here were based on weighted cases.

\subsection{Sample}

Previous research demonstrates that immigration status, religiosity, and religion are important factors in determining the living arrangements of couples in Israel (Katz 2001; Bystrov 2012). The current research analyzes a subsample of the Israeli population that includes only native-born secular Jews, thus allowing us to focus on the effects of ethnicity, education, and labor market activity. The native-born restriction is important because ideational theories treat education as a proxy for cultural endowment and immigrants may have acquired some or all of their education in a different cultural setting than Israel.

In order to focus on never-married cohabiting couples as opposed to postmarital cohabitation, the separated, divorced, and widowed were dropped from the sample. Respondents in a second- or a higher-order marriage were dropped from the sample as well. This is important, because the factors affecting nubile cohabitation may differ from those related to postmarital cohabitation (see, e.g., Oppenheimer 2003: 130-131).

Although the ISS includes adults aged 20 and over, the current analysis does not include those aged 20-22 because very few of them are cohabiting or married at these ages. In addition, very few of them have managed to obtain a BA degree, due in part to mandatory military or national service for men and women aged 18-21 and 18-20 respectively. 
People older than 31 were also excluded from the analysis in order to focus on the ages when there are only a limited number of individuals who are divorced or who are in their second- or higher-order marriage. ${ }^{5}$ Same-sex couples were also excluded from this analysis. This is because they cannot be legally married in Israel at this time and therefore do not have the choice between the three living arrangements discussed in this paper. $^{6}$

The sample $(\mathrm{n}=1,756)$ includes secular native-born Jewish men and women aged 23-31 who have never married or were married for the first time at the time of the survey. ${ }^{7}$

\subsection{Methods}

In order to examine current living arrangements among secular Jewish young adults we employ multinomial logit regression. This approach allows an examination of the connection between ethnicity, current educational and employment traits, and current living arrangements of men and women, while controlling for the age of the respondent and the period in which $\mathrm{s} / \mathrm{he}$ was questioned. We run a multinomial logit model, for men and women separately, to find out how ethnicity and educational and employment traits are associated with a person's odds of cohabiting vs. being married, and of cohabiting vs. being unpartnered.

Because this research examines current living arrangements, it is not possible to separate the event of cohabitation and the length of the cohabitation period. However, for every theory the same logic can be applied for interpreting both phenomena. For example, according to the career uncertainty hypothesis, we would expect cohabitation periods to be longer for the less educated, thus increasing the odds of cohabiting at the survey date. According to ideational theories, we would expect the more liberal attitudes of the more educated to allow for longer periods of cohabitation and even the embracing of cohabitation as an alternative lifestyle. We also note that, given the crosssectional nature of the data, we must exercise caution in interpreting the direction of relationships between different current-status measures, such as current marital status, student status, and current labor market activities, as relationships may operate in more than one direction.

\footnotetext{
${ }^{5}$ Of secular native-born Jewish young adults aged 23-31, 69\% were never married (single), 29\% were in their first marriage, and only $2 \%$ were separated, divorced, widowed, or in a higher-order marriage.

${ }^{6}$ Among the Jewish secular native-born aged 23-31 who were never married or were married for the first time $(n=1,762), 0.39 \%$ were part of a same-sex coresidential couple. Out of those living with a partner $(\mathrm{n}=693), 0.95 \%$ lived with a partner of the same sex.

${ }^{7}$ Married people who did not report living with a partner were dropped from the sample.
} 
In light of the discussion of the Israeli setting above, we note that factors such as educational attainment, student status, labor market activity, and ethnicity may be associated with union status and related family-building processes. In particular, because the purchase of a residential home and childbearing occur after marriage in the vast majority of cases, the choice of current living arrangements is likely to be closely related to short-term plans for the establishment of a stable household with dependants. Because childbearing occurs after marriage, we did not include parenthood status as a predictor of living arrangements; nonetheless the association between marital status and parenthood status should be considered when interpreting the empirical results. ${ }^{8}$

\subsection{Measurements}

We present descriptive statistics on the variables examined in the Appendix. The variables are as follows

Current living arrangements. The outcome variable will measure the current living arrangements of the individual. Respondents of the ISS are asked to report on their marital status (married, separated, divorced, widowed, or single). However, they are not asked whether they are currently cohabiting or have ever cohabited. The current research will make use of information available in the ISS on the relationship of each of the household members to the respondent. If the respondent is currently married for the first time and living with a partner, then $\mathrm{s} / \mathrm{he}$ is classified as married. If the respondent has never married and is living with a partner, then s/he is considered to be currently cohabiting. If the respondent has never married and is not living with a partner, then $\mathrm{s} /$ he is considered unpartnered.

Age. Age was measured on an interval scale ranging from 23 to 31 .

Period. To control for period changes in marriage and cohabitation, a dummy variable was created where the years 2005-2006 were coded as 0 and the years 2007-2009 were coded as 1 .

Ethnic origin. Because the sample includes only the native-born, ethnic origin was measured by the country in which the respondent's mother was born. ${ }^{9}$ The countries were grouped to create three categories: (1) third-generation Israeli - the respondent's mother was born in Israel; (2) African-Asian origin - the respondent's

\footnotetext{
${ }^{8}$ The near absence of childbearing among unmarried individuals is apparent in our sample; among cohabiting women and men ( $\mathrm{n}=113$ and $\mathrm{n}=86)$ only $2 \%$ and $3 \%$ reported having had children and among unpartnered women and men ( $\mathrm{n}=485$ and $\mathrm{n}=584)$ only $2 \%$ and none reported having had children.

${ }^{9}$ It was not possible to use a variable that accounts for both the mother's and the father's country of birth because the category of mixed origin (mother born in Africa/Asia and father born in Europe/America, or vice versa) included a very small number of respondents.
} 
mother was born in Africa or Asia (reference category); (3) European-American origin - the respondent's mother was born in Europe or America.

School enrollment status. Respondents who are currently studying and report that the last school they attended was an academic institution are classified as students. ${ }^{10}$

Educational level. The 'highest diploma received' was recoded into a dummy variable which indicates whether or not it is an academic diploma (BA or higher degree). ${ }^{11}$

Work experience. The reported total number of years worked in all workplaces (in Israel and/or abroad) was grouped into three categories: (1) 0-4 years; (2) 5-9 years (reference category); (3) 10 years or more.

Work status. The respondent reported on whether s/he is currently working (as an employee or self-employed) and on the number of habitual weekly hours of work. This information was used to create three categories of work status: (1) does not work (reference category); (2) part-time work (works less than 35 hours); (3) full-time work (works 35 hours or more). ${ }^{12}$

\subsection{Results}

\subsubsection{Descriptive results}

Most of the secular native-born Jewish men and women aged 23-31 are unpartnered $(59 \%)$. The rest are cohabiting (12\%) or married (29\%). This distribution varies by age and sex. Figures 1 and 2 show the distribution of living arrangements, by age, among men and women respectively. As expected, the proportion of those married rises with age and of those living without a partner decreases.

\footnotetext{
${ }^{10}$ In the current context the vast majority (83\%) of students are enrolled in academic programs; the remainder $(17 \%)$ are enrolled in a variety of postsecondary or vocational studies, some of which may be undertaken as part of on-the-job training. Empirical results are robust to differing definitions of student status (including or excluding those who study in nonacademic programs).

${ }^{11}$ According to Goldstein and Kenney (2001), for more recent cohorts college graduation is a clearer dividing line than high school graduation in both labor and marriage markets. For statistics on the distribution of the highest diploma received in the current research, see Appendix.

${ }_{12}$ Respondents who reported being currently in the army were excluded from the analysis. This is due to the fact that the small number of respondents currently in the army did not allow us to add a fourth 'work status' category of 'regular army.' In addition, 10 respondents who reported being members of a kibbutz (rather than employees) were excluded from the analysis because the meaning of work instability could be different for kibbutz members.
} 


\section{Figure 1: Distribution of living arrangements among men, by age}

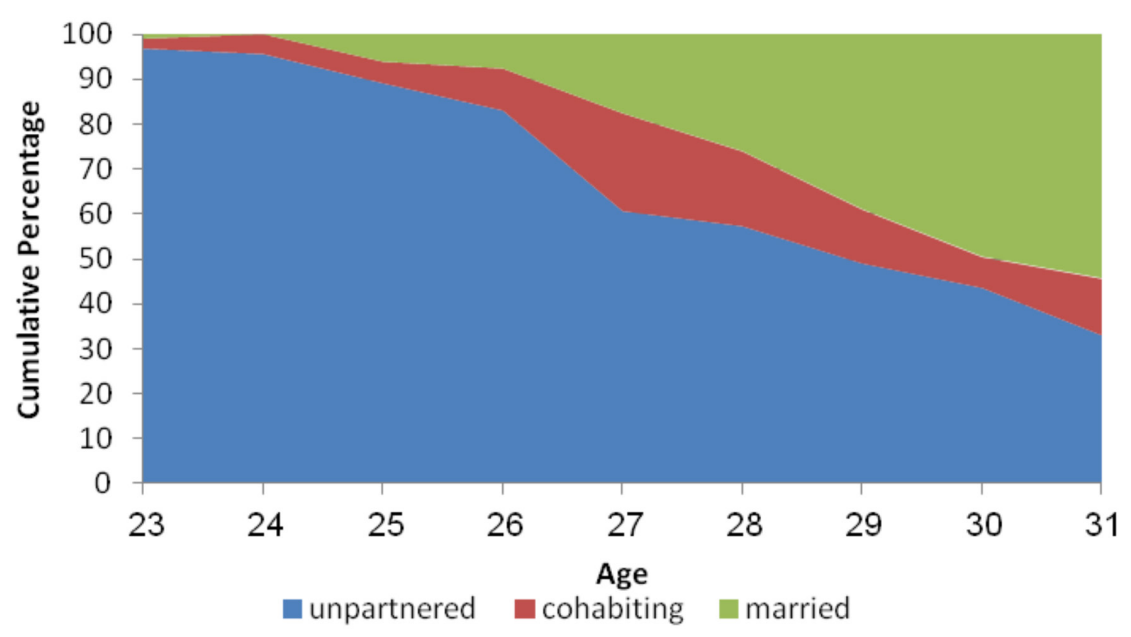

Source: Israel Social Survey 2005-2009, secular native-born Jewish men aged 23-31 who never married or are married for the first time $(n=853)$.

Note: Size of sample for the different ages varies between 75 and 115 .

Figure 2: Distribution of living arrangements among women, by age

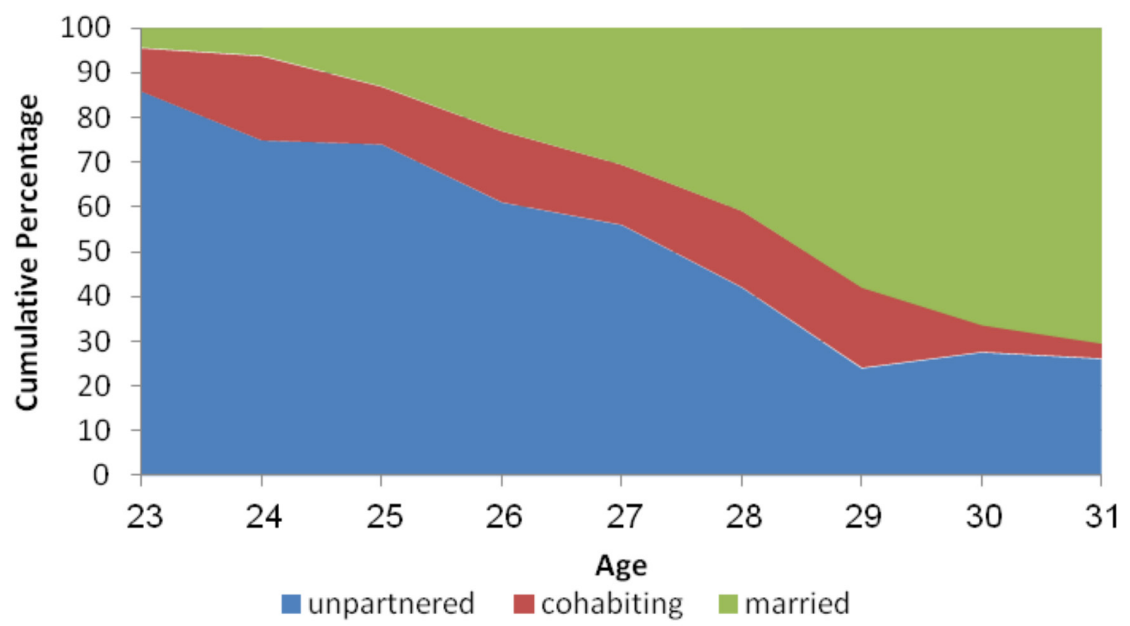

Source: Israel Social Survey 2005-2009, secular native-born Jewish women aged 23-31 who never married or are married for the first time $(n=903)$.

Note: Size of sample for the different ages varies between 88 and 115 . 
These trends are evident among both men and women, but the proportion married at each age is higher among women. For example, among secular native-born Jewish women $31 \%$ are married at age 27 and $70 \%$ are married at age 31 . Among secular native-born Jewish men $18 \%$ are married at age 27 and 54\% are married at age 31 . With regard to cohabitation the age pattern is less clear. Nevertheless, women's earlier initiation of the 'marriage process' is evident also in the levels of cohabitation. For example, among men there is a large proportion cohabiting at age $27(22 \%)$, while among women the proportion cohabiting reaches a maximum at age $24(19 \%)$. A reasonable explanation for the patterns observed is that women start the 'marriage process' of premarital cohabitation, often followed by separation or marriage, at a younger age than men.

\subsubsection{Regression results}

Table 1 presents exponentiated coefficients from a multinomial logit regression of living arrangements for men and women separately. ${ }^{13}$

Table 1: Exponentiated coefficients from a multinomial logit regression of living arrangements, by sex

\begin{tabular}{|c|c|c|c|c|}
\hline & \multicolumn{2}{|l|}{ Male } & \multicolumn{2}{|l|}{ Female } \\
\hline & $\begin{array}{l}\text { Cohabiting } \\
\text { vs. } \\
\text { Married }\end{array}$ & $\begin{array}{l}\text { Cohabiting } \\
\text { vs. } \\
\text { Unpartnered }\end{array}$ & $\begin{array}{l}\text { Cohabiting } \\
\text { vs. } \\
\text { Married }\end{array}$ & $\begin{array}{l}\text { Cohabiting vs. } \\
\text { Unpartnered }\end{array}$ \\
\hline Age & $0.76^{* * *}$ & $1.22^{* *}$ & $0.62^{\star * \star}$ & 1.03 \\
\hline Period (2007-2009) & 1.19 & 1.04 & 1.36 & 1.39 \\
\hline \multicolumn{5}{|l|}{ Ethnic origin } \\
\hline Third-generation Israeli & 0.82 & 1.63 & $2.53^{*}$ & $2.27^{*}$ \\
\hline African-Asian origin & Ref. & Ref. & Ref. & Ref. \\
\hline European-American origin & 0.69 & 1.10 & $3.81^{* *}$ & $3.58^{* *}$ \\
\hline $\begin{array}{l}\text { School enrollment status } \\
\text { (Student) }\end{array}$ & $2.30^{* *}$ & $2.14^{\star *}$ & $1.74^{*}$ & 0.93 \\
\hline \multicolumn{5}{|c|}{$\begin{array}{l}{ }^{13} \text { No multicollinearity effects were detected. Tolerance values varied between } 0.49792 \text { and } 0.98791 \text { for the } \\
\text { sample of men and between } 0.53914 \text { and } 0.98184 \text { for the sample of women (corresponding to a VIF of } \\
1.01224-2.00837 \text { for men and } 1.01850-1.85482 \text { for women). In order to examine the necessity of all three } \\
\text { categories in the outcome variable (married/ cohabiting/ unpartnered), a Wald chi-square test was performed } \\
\text { testing the null hypothesis that the coefficients of the first equation are identical to the corresponding } \\
\text { coefficients in the second equation. The null hypothesis was rejected }(\mathrm{p}<0.001) \text {. }\end{array}$} \\
\hline
\end{tabular}


Table 1: (Continued)

\begin{tabular}{lllll}
\hline & \multicolumn{3}{l}{ Male } & \multicolumn{2}{l}{ Female } \\
\cline { 2 - 5 } & $\begin{array}{l}\text { Cohabiting } \\
\text { vs. } \\
\text { Married }\end{array}$ & $\begin{array}{l}\text { Cohabiting } \\
\text { vs. } \\
\text { Unpartnered }\end{array}$ & $\begin{array}{l}\text { Cohabiting } \\
\text { vs. } \\
\text { Married }\end{array}$ & $\begin{array}{l}\text { Cohabiting vs. } \\
\text { Unpartnered }\end{array}$ \\
\hline $\begin{array}{l}\text { Educational level (BA or a } \\
\text { higher degree) } \\
\text { Work experience }\end{array}$ & $1.99^{*}$ & $2.28^{* *}$ & $1.68^{*}$ & $1.61^{+}$ \\
$\begin{array}{l}\text { 0-4 years } \\
\text { 5-9 years }\end{array}$ & $3.68^{* *}$ & 0.96 & 0.59 & 0.66 \\
$\begin{array}{l}\text { 10 years or more } \\
\text { Work status }\end{array}$ & $\begin{array}{l}\text { Ref. } \\
\text { Does not work }\end{array}$ & Ref. & Ref. & Ref. \\
Part-time work & 1.13 & 0.80 & 0.75 \\
Full-time work & Ref. & Ref. & Ref. & Ref. \\
Generalized R-Square & 1.22 & 1.57 & $2.03^{+}$ & 1.68 \\
\hline $\mathrm{N}$ & 0.72 & $2.47^{*}$ & $2.18^{*}$ & $1.75^{+}$ \\
\hline
\end{tabular}

Source: Israel Social Survey 2005-2009, secular native-born Jewish men and women aged 23-31 who never married or are married for the first time.

Notes: ${ }^{+} p<0.1,{ }^{*} p<0.05,{ }^{* *} p<0.01,{ }^{* \star *} p<0.001$

\subsubsection{Educational characteristics and labor market activity and experience: Cohabitation vs. marriage}

\section{Among men}

Results concerning educational characteristics and labor market activity and experience provide support for ideational theories and mixed support for the economic theories. In particular, more educated men have nearly twice the odds of cohabiting vs. being married; this result is consistent with ideational theories, but runs counter to the predictions of the economic theories. Men who are students, and thus on their way to completing higher education, are also more likely to be cohabiting - a finding consistent with ideational theories as well as with the career uncertainty hypothesis. Men with little work experience ( $0-4$ years) are also more likely to be cohabiting than to be married; this result is consistent with both of the economic theories. Working full- 
time is not significantly associated with the odds of cohabiting vs. being married, which runs counter to the predictions of the economic theories.

\section{Among women}

Among women there is also support for ideational theories and mixed support for the economic theories. More educated women are more likely to be involved in a cohabiting union than their less educated counterparts; this result is consistent only with ideational theories and the theory of comparative advantage. Also students are more likely to be cohabiting; this is consistent with ideational theories and the theory of career uncertainty. There are no statistically significant associations with accumulated work experience; this runs counter to the economic theories, particularly that of comparative advantage. Full-time employment is associated with increased odds of cohabitation - a result consistent with the theory of comparative advantage. However, it is important to keep in mind that an alternative interpretation for this finding is that women who have given birth or are planning childbirth in the near future are less likely to be employed full-time (due to issues of work-family balance) and are also more likely to be married than to be cohabiting, in the current context.

\subsubsection{Educational characteristics and labor market activity and experience: Cohabitation vs. being unpartnered}

Results here provide partial support for the theory of career uncertainty; the other theories do not have unambiguous predictions regarding the comparison between cohabitation and being unpartnered. Higher levels of education are associated with higher odds of cohabitation vs. being unpartnered, for both men and women (the results for women are marginally significant); these findings are consistent with the theory of career uncertainty. Regarding accumulated work experience and full-time employment, only the results for full-time employment are consistent with the theory of career uncertainty (again results for women are marginally consistent). Results regarding accumulated work experience are not statistically significant. Student status is associated with higher odds of cohabitation vs. being unpartnered among men; this runs counter with the prediction from the career uncertainty hypothesis. 


\subsubsection{Ethnic differences: Cohabitation vs. marriage}

Ideational theories are partially supported by the results concerning ethnic differences. (Other theories have no predictions regarding ethnic differences.) Results for women are consistent with the theory in that women of European-American origin as well as third-generation Israelis have two to four times higher odds of being involved in cohabiting unions, as compared to their African-Asian counterparts. Results for men are not statistically significant. ${ }^{14}$

\section{Discussion and conclusions}

This research aimed to explore the relationships between ethnicity, education, and employment characteristics, on the one hand, and living arrangements, on the other, among native-born secular Jewish young adults in Israel. Three central theories were tested: (1) the gains from marriage as suggested by economic theories of comparative advantage; (2) the career uncertainty hypothesis; and (3) ideational theories.

\subsection{Economic theory of comparative advantage}

Economic theories of comparative advantage predict associations between educational and employment characteristics of men and women and the odds of cohabitation vs. marriage. In terms of educational variables, the empirical findings are not consistent with this theory for men, although they are consistent for women. In terms of the labor market variables, the results are not uniformly consistent with the theory for men or for women. In particular, the finding that women with little labor market experience are no more likely to cohabit than women with considerable experience is strikingly inconsistent with the theory. While the finding that women working full-time have higher odds of cohabiting vs. being married than women not currently working may be seen as consistent with theories of comparative advantage, there is an alternative interpretation for this finding. In particular, women who have given birth or are planning childbirth in the near future are less likely to be employed full-time (due to issues of work-family balance) and are also more likely to be married than to be cohabiting, in the current context. It is therefore reasonable to assume that the effect of work status is not related to Becker's theory. Overall, the empirical results are in many cases inconsistent with the theory of the gains to trade for men as well as for women.

\footnotetext{
${ }^{14}$ The results do not change if ethnic origin is defined via the father's country of birth.
} 


\subsection{Career uncertainty}

In terms of the educational and employment variables, the empirical results are not consistently in line with the career uncertainty hypothesis. For example, men who are employed full-time (as compared to those not employed) are not significantly less likely to cohabit than to be married. Also in contrast to the theory's predictions, higher educational attainment was found to increase rather than decrease the odds of cohabiting vs. being married.

However, other findings fit well within the career uncertainty framework. According to Oppenheimer (2003), men's level of career maturity should be negatively related to the odds of cohabitation vs. marriage. In line with this hypothesis, it was found in the current research that men with $0-4$ accumulated years of work experience have higher odds of cohabiting (vs. being married) than men with 5-9 years of work experience. Interestingly, 10 years or more of work experience did not significantly improve the odds of being married, in comparison to men with 5-9 years of work experience. A possible explanation for this last finding is that the first years of labor market work are more often characterized by career uncertainty, which places obstacles on the assortative mating process and discourages marriage. However, after a certain threshold of career maturity is reached there is less uncertainty about the future and thus the number of accumulated years of experience is no longer related to the odds of marriage.

In contrast to the effects of accumulated work experience among men, no such effects were found for women; this difference supports Oppenheimer's argument that men, rather than women, preserve their role as the main providers of the economic foundation for a union. The fact that women's work experience is not associated with cohabitation vs. marriage also supports previous findings from Israel indicating that women are considered secondary breadwinners and are expected to combine work and family life (Kraus 2002; Raz-Yurovich 2010).

\subsection{Ideational theories}

Support for ideational theories can be found in Israel in that sociocultural groups such as Arabs and religious Jews rarely cohabit. Our findings of higher odds of cohabitation vs. being married among third-generation Israeli women, as well as among women of European-American origin, indicate that cultural values and norms may indeed play an important role in the spread of cohabitation, even among native-born secular Jews, who are thought to be the forerunners of SDT in Israel. 
The role of ethnicity may be understood in terms of generational relationships within the family (Rosina and Fraboni 2004), whereby favorable attitudes toward cohabitation among both young women and their parents are important in establishing a cohabitating partnership. That is, native-born Israeli women whose parents were born in countries of North Africa and Asia may not provide the parental support and tolerance of cohabitation experienced by their European-American-origin counterparts, thus dampening their odds of living in a cohabiting union. It is interesting that ethnic origin had no effect on the odds of cohabitation among men. A possible explanation is that men are less subject to social control with regard to the choice of living arrangements and thus their parents' origin does not significantly affect their odds of cohabiting. The higher odds of cohabitation for third-generation Israeli women than for women of African-Asian origin can be a result of the adoption of a local culture that is relatively tolerant of nontraditional living arrangements.

According to ideational theories, we would expect more educated individuals, as well as students who are in the process of working toward academic degrees, to have higher odds of cohabiting vs. being married due to the more liberal attitudes they tend to hold. This hypothesis is confirmed by the current research for both men and women. It is important to note that if immigrants had been included in the analysis the connection between education and cohabitation might have been different, since less educated individuals were often the forerunners of cohabitation in the former Soviet Union (Sobotka 2008). It will be interesting to examine in the future whether the second generation of the 1990s wave of immigration from the former Soviet Union, who are now becoming native-born young adults, will exhibit different patterns than those of the native-born young adults observed in the current research.

In conclusion, we find that in Israel, and perhaps in other countries as well, a multicausal model that takes into consideration both ideational and economic factors is appropriate for explaining living arrangements among young adults. Future studies on cohabitation in Israel will benefit from a micro-level multivariate analysis that includes direct measures of attitudes (e.g., emancipative values) and of economic and educational status. A longitudinal data set will be especially useful in establishing causality between the individual's characteristics and his/her subsequent living arrangements.

\section{Acknowledgments}

This research was supported by The Israel Science Foundation (grant no. 939/11) and the Levi Eshkol Fund of the Hebrew University of Jerusalem. A previous version of this paper was presented at the 2014 Israel Sociological Society Meeting in Tel Aviv. The 
authors acknowledge the assistance of the Israel Social Science Data Archive and the Israel Central Bureau of Statistics in making the data accessible. In addition, the authors thank Ms. Shlomit Kagya for assistance in preparation of the data files. Finally, the authors would like to thank the reviewers and editor of this paper for their very useful comments and suggestions. 


\section{References}

Baloush-Kleinman, V. and Sharlin, S.A. (2004). Social, economic, and attitudinal characteristics of cohabitation in Israel. Journal of family and economic issues 25(2): 255-269. doi:10.1023/B:JEEI.0000023641.81143.43.

Bar-Haim, E., Blank, C., and Shavit, Y. (2013). Educational opportunity, employment and income: 1995-2008. Taub Center for Social Policy Studies in Israel: 1-22. Policy Paper Series No. 2013.09.

Batalova, J.A. and Cohen, P.N. (2002). Premarital cohabitation and housework: Couples in cross-national perspective. Journal of Marriage and Family 64(3): 743-755. doi:10.1111/j.1741-3737.2002.00743.x.

Baxter, J. (2005). To marry or not to marry: Marital status and the household division of labor. Journal of Family Issues 26(3): 300-321. doi:10.1177/0192513X0 4270473.

Becker, G.S. (1991). A treatise on the family. Cambridge: Harvard University Press.

Blossfeld, H.P. (1995). Changes in the process of family formation and women's growing economic independence: A comparison of nine countries. In: Blossfeld, H.P. (ed.). The new role of women: Family formation in modern societies. Boulder: Westview Press: 3-32.

Bumpass, L. and Lu, H.H. (2000). Trends in cohabitation and implications for children's family contexts in the United States. Population Studies 54(1): 29-41. doi:10.1080/713779060.

Bystrov, E. (2012). The second demographic transition in Israel: One for all? Demographic Research 27(10): 261-298. doi:10.4054/DemRes.2012.27.10.

Carmichael, G.A. (1995). Consensual partnering in the more developed countries. Journal of the Australian Population Association 12(1): 51-86. doi:10.1007/ BF03029310.

Dominguez Folgueras, M. (2013). Is cohabitation more egalitarian? The division of household labor in five European countries. Journal of Family Issues: 34(12): 1623-1646. doi:10.1177/0192513X12464948.

Fogel, N. (2005). Cohabitation in Israel. Jerusalem: Israel Central Bureau of Statistics [In Hebrew].

Fogiel-Bijaoui, S. (1999). Families in Israel: Between familism and post-modernism. In Izraeli, D.N., Friedman, A., Dahan-Kalev, H., Fogiel-Bijaoui, S., Herzog, H., 
Hasan, M., and Naveh, H. (eds.). Sex, gender, politics: Women in Israel. TelAviv: Hakibbutz hameuchad: 107-166.

Fogiel-Bijaoui, S. (2002). Familism, postmodernity and the state: The case of Israel. The Journal of Israeli History 21(1-2): 38-62. doi:10.1080/1353104021 2331295852.

Friedlander, D. and Goldscheider, C. (1978). Immigration, social change and cohort fertility in Israel. Population Studies 32(2): 299-317. doi:10.1080/00324728. 1978.10410716.

Glickman, A., Oren, A., and Lewin-Epstein, N. (2003). The marriage institute in Israel at the beginning of the $21^{\text {st }}$ Century. Deot Ba'am 7, Tel-Aviv: The B.I. and Lucille Cohen Institute for Public Research, Tel-Aviv University [In Hebrew].

Goldstein, J.R. and Kenney, C.T. (2001). Marriage delayed or marriage forgone? New cohort forecasts of first marriage for US women. American Sociological Review 66(4): 506-519. doi:10.2307/3088920.

Haberfeld, Y. and Cohen, Y. (2007). Gender, ethnic, and national earnings gaps in Israel: The role of rising inequality. Social Science Research 36(2): 654-672. doi:10.1016/j.ssresearch.2006.02.001.

Heuveline, P. and Timberlake, J.M. (2004). The role of cohabitation in family formation: The United States in comparative perspective. Journal of Marriage and Family 66(5): 1214-1230.

Hoem, J.M. (1986). The impact of education on modern family-union initiation. European Journal of Population 2(2): 113-133. doi:10.1007/BF01796886.

ICBS (2012). Tertiary education in Israel: 2008/9. Jerusalem: Israel Central Bureau of Statistics. http://www.cbs.gov.il/publications12/1475_haskhala_gvoha08_09/ pdf $/ \mathrm{h}$ p print.pdf. In Hebrew [Accessed in January 2013]

ICBS (2013). Statistilite 133: Women \& Men in Israel 1990-2011. Jerusalem: Israel Central Bureau of Statistics. http://www.cbs.gov.il/www/statistical/mw2 013_h.pdf. In Hebrew [Accessed in July 2013].

ICBS (2014). Statistical abstract. Jerusalem: Israel Central Bureau of Statistics.

Kalmijn, M. (2011). The influence of men's income and employment on marriage and cohabitation: Testing Oppenheimer's theory in Europe. European Journal of Population 27(3): 269-293. doi:10.1007/s10680-011-9238-x. 
Katz, R. (2001). Effects of migration, ethnicity and religiosity on cohabitation. Journal of Comparative Family Studies 32(4): 587-599

Kiernan, K. (2000). European perspectives on union formation. In: Waite, L.J., Bachrach, C., Hindin, M., Thomson, E., and Thornton, A. (eds.). The ties that bind: Perspectives on marriage and cohabitation. Hawthorne: Aldine de Gruyter: $40-58$.

Kiernan, K. (2001). The rise of cohabitation and childbearing outside marriage in western Europe. International Journal of Law, Policy and the Family 15(1): 121. doi:10.1093/lawfam/15.1.1.

Kiernan, K. (2004). Unmarried cohabitation and parenthood in Britain and Europe. Law \& Policy 26(1): 33-55. doi:10.1111/j.0265-8240.2004.00162.x.

Kraus, V. (2002). Secondary breadwinners: Israeli women in the labor force. Westport: Praeger Publishers.

Lavee, Y. and Katz, R. (2003). The family in Israel. Marriage and Family Review 35(1-2): 193-217. doi:10.1300/J002v35n01_11.

Lesthaeghe, R. (1998). On theory development: Applications to the study of family formation. Population and Development Review 24(1): 1-14. doi: $10.2307 / 2808120$.

Lesthaeghe, R. (2010). The unfolding story of the second demographic transition. Population and Development Review 36(2): 211-251. doi:10.1111/j.1728-4457. 2010.00328.x.

Lesthaeghe, R. and Surkyn, J. (1988). Cultural dynamics and economic theories of fertility change. Population and Development Review 14(1): 1-45. doi:10.2307/ 1972499.

Manor, A. (2013). Cohabitation among secular Jews in Israel. [M.A. thesis]. Department of Sociology and Anthropology, The Hebrew University of Jerusalem.

Ní Bhrolcháin, M. and Beaujouan, É. (2013). Education and cohabitation in Britain: A return to traditional patterns? Population and Development Review 39(3): 441-458. doi:10.1111/j.1728-4457.2013.00611.x.

OECD (2010). SF3.3: Cohabitation rate and prevalence of other forms of partnership. Paris: OECD. http://www.oecd.org/dataoecd/52/27/41920080.pdf. [Accessed in July 2013.] 
Okun, B.S. (2013). Fertility and marriage behavior in Israel: Diversity, change and stability. Demographic Research 28(17): 457-504. doi:10.4054/DemRes.2013. 28.17 .

Okun, B.S. (2016). An investigation of the unexpectedly high fertility of secular, native-born Jews in Israel. Population Studies 70(2): 239-257. doi:10.1080/ 00324728.2016 .1195913$.

Okun, B.S. and Khait-Marelly, O. (2008). Demographic behaviour of adults of mixed ethnic ancestry: Jews in Israel. Ethnic and Racial Studies 31(8): 1357-1380. doi:10.1080/01419870701719071.

Oppenheimer, V.K. (1988). A theory of marriage timing. American Journal of Sociology 94(3): 563-591. doi:10.1086/229030.

Oppenheimer, V.K. (2003). Cohabiting and marriage during young men's careerdevelopment process. Demography 40(1): 127-149. doi:10.2307/3180815.

Perelli-Harris, B. (2014). How similar are cohabiting and married parents? Second conception risks by union type in the United States and across Europe. European Journal of Population 30(4): 437-464. doi:10.1007/s10680-014-9320-2.

Perelli-Harris, B., Sigle-Rushton, W., Kreyenfield, M., Lappegard, T., Keizer, R., and Berghammer, C. (2010). The educational gradient of childbearing within cohabitation in Europe. Population and Development Review 36(4): 775-801. doi:10.1111/j.1728-4457.2010.00357.x.

Peres, Y. and Katz, R. (1980). Family and familism in Israel. Megamot 26: 37-55 [In Hebrew].

Raley, R.K. (2000). Recent trends and differentials in marriage and cohabitation: The United States. In: Waite, L.J., Bachrach, C., Hindin, M., Thomson, E., and Thornton, A. (eds.). The ties that bind: Perspectives on marriage and cohabitation. Hawthorne: Aldine de Gruyter: 19-39.

Raz-Yurovich, L. (2010). Men's and women's economic activity and first marriage: Jews in Israel, 1987-1995. Demographic Research 22(29): 933-964. doi:10.4054/DemRes.2010.22.29.

Rosina, A. and Fraboni, R. (2004). Is marriage losing its centrality in Italy? Demographic Research 11(6): 149-172. doi:10.4054/DemRes.2004.11.6.

Schellekens, J. and Gliksberg, D. (2013). The decline in marriage: An age-periodcohort analysis, Israel 1961-2007. Paper presented at the Annual Meeting of the Population Association of America, New Orleans. 
Sobotka, T. (2008). The diverse faces of the Second Demographic Transition in Europe. Demographic Research 19(8): 171-224. doi:10.4054/DemRes.2008.19.8.

Sobotka, T. and Toulemon, L. (2008). Changing family and partnership behaviour: Common trends and persistent diversity across Europe. Demographic Research 19(6): 85-138. doi:10.4054/DemRes.2008.19.6.

Toren, N. (2003). Tradition and transition: Family change in Israel. Gender Issues 21(2): 60-76. doi:10.1007/s12147-003-0017-9.

United Nations (2011). International human development indicators [electronic resource]. http://hdr.undp.org/en/data/trends. 


\section{Appendix}

Table A-1: Descriptive statistics (percentages)

\begin{tabular}{llll}
\hline & Men & Women & All \\
\hline Period (2007-2009) & 59 & 58 & 51 \\
Ethnic origin & & & 59 \\
Third-generation Israeli & 63 & 62 & 63 \\
African-Asian origin & 17 & 17 & 17 \\
European-American origin & 20 & 21 & 20 \\
School enrollment status (Student) & 31 & 35 & 33 \\
Highest diploma received & & & \\
None & 3 & 1 & 2 \\
Secondary & 16 & 8 & 12 \\
Matriculation & 42 & 40 & 41 \\
Postsecondary & 13 & 11 & 12 \\
BA & 21 & 34 & 28 \\
MA & 4 & 6 & 5 \\
PhD & 0.11 & 0.13 & 0.12 \\
Work experience & & & \\
0-4 years & 37 & 28 & 32 \\
5-9 years & 45 & 48 & 47 \\
10 years or more & 18 & 24 & 21 \\
Work status & & & \\
Does not work & 19 & 22 & 20 \\
Part-time work & 19 & 24 & 21 \\
Full-time work & 62 & 54 & 59 \\
Living arrangements & & & \\
Unpartnered & 67 & 52 & 27.0 \\
Cohabiting & 10 & 13 & \\
Married & 23 & 27.0 & \\
Age (mean) & & & \\
\hline & & & \\
\hline
\end{tabular}

Source: Israel Social Survey 2005-2009, secular native-born Jewish men and women aged 23-31 who never married or are married for the first time $(n=1,756)$. 